\title{
Where were you August 8, 1985?
}

\author{
ROBERT I. REYNOLDS and HAROLD TAKOOSHIAN \\ Fordham University at Lincoln Center, New York, New York
}

\begin{abstract}
In February 1987, President Reagan challenged reporters at a press conference to "remember what they were doing on August 8, 1985." In this experiment, 35 subjects were given 5 min to recall personal episodes from that date, 19 months earlier. All subjects were able to give a general recollection of where they had been and what they had been doing. Fifty-four percent gave details of personal episodes that distinguished that day from all others. The specific protocols contain significantly more negative accounts than do the general protocols. The implications and limitations of the study are discussed.
\end{abstract}

In February 1987, in the midst of the Iran-Contra debate, President Ronald Reagan challenged reporters at a press conference: "Everybody who can remember what they were doing on August 8,1985, raise your hand." The following day, one of the authors posed this question to 33 students at Fordham University. Twenty-four of the $33(76 \%)$ students were able to reconstruct personal episodes that occurred on that date (Reynolds, 1987).

The rate of forgetting of real-life episodes is apparently different from the rate of forgetting during traditional experimental studies that test recall of nonsense material. Linton (1975), for example, found that the forgetting curve for personal episodes is a straight-line function of relatively modest slope (5\% per year). Sheingold and Tenney (1982) found that detailed recall of the circumstances of the birth of a younger sibling does not decrease over time.

It has been suggested that recall of personal episodes persists longer than recall during laboratory studies because the material makes contact with a richer network of associations. In some ways, the process is similar to the recall of stories in which the subject retains the story's essential meaning or gist and then fills in the details so as to make a coherent narrative. In comparison with memory for someone else's story, the recollection of episodes from one's life story is much richer in details important to the individual. Glass and Holyoak (1986) suggested that we begin the search by finding some known temporal landmark from which we can home-in on the target event. We then generate details that were likely to have happened and deal with those (possible) details as we would a recognition task.

A temporal landmark can be some personally relevant event, such as a birthday, or some shared event, such as the assassination of President Kennedy. Temporal landmarks can vary in their vividness and emotional associa-

Reprint requests should be sent to Robert Reynolds, Division of Social Sciences, Room 916, Fordham University at Lincoln Center, New York, NY 10023. tions. So-called flashbulb memories are vivid reconstructions of personal events that persist throughout one's life. Colegrove (1899) posed the question, "Where were you when you heard that Lincoln was assassinated?" He found that, 33 years after the event, 127 out of $179(72 \%)$ individuals he interviewed could recall what they had been doing. In general, the greater the consequences of an event the more vivid its recollection will be (Brown \& Kulik, 1977).

In our research, we provided subjects a temporal landmark, namely that the target date was "the second Thursday of August two summers ago." We were particularly interested in the extent to which subjects could reconstruct a given target date, the degree of specificity of their recall, and the type of episode that was recalled.

\section{METHOD}

Thirty-five Fordham University undergraduate students participated as subjects. The students were tested en masse in two psychology night classes during mid-March of 1987.

The subjects were provided a sheet with the question printed on top, "Where was I on August 8, 1985?" Three-fourths of a page was provided for their protocols. At the bottom were provided spaces to indicate (1) their confidence in their recall $(0 \%$ to $100 \%)$, (2) their attitude toward President Reagan prior to August 8, 1985 (strongly approved, approved, disapproved, strongly disapproved ), and (3) whether they had a means of verifying their recollection.

The researcher read the question to the subjects, explained that the target date was the second Thursday of August two summers ago, and encouraged them to be as specific as possible in their recollection of the events of that day. The subjects were further informed that they had $5 \mathrm{~min}$ to complete the sheet. Five minutes later, the data sheets were collected.

\section{RESULTS}

Each protocol was evaluated by the researchers as to its being a general or specific description. General recollections place the individual in a particular setting, and give in a general way the activities of the day (e.g., "I was vacationing in Bermuda with my husband and another couple who are very close friends of ours'). Protocols were considered specific if they gave some detailed 
information that distinguished August 8, 1985, from any other day in that individual's life, for example,

Traveled back to Wapahonita, Ohio, from a visit to Niagara Falls, Ontario. Left a Best Western in Erie, Pennsylvania, drove through Cleveland, Ohio, to my sister's in Fiffin, Ohio. Took my niece to a movie-had pizza at my sister's pizza shop; stayed there the night.

One hundred percent of the subjects had a general recollection of where they had been and what they had been doing there. By comparison, $54 \%$ had specific recall of details that distinguished that day.

Confidence ratings for accuracy of recall were high: the mean was $80.42 \%$. Confidence ratings were the same for those who recalled specific details $(80.26 \%)$ as for those who had only a general recollection $(80.64 \%)$. For some reason unknown to us, the subjects who had favored President Reagan were also more confident in their judgments. The correlation between certainty and attitude toward President Reagan is $r=+.376, p=.03$. By comparison, there is no relationship between specificity of recall and attitude toward the President $(r=+.116$, $p=.51)$.

We were able to pursue the question of subjects' accuracy in only five cases. Of these, three recollections were completely confirmed, one was partially accurate, and the other was fallacious.

Protocols were also evaluated as to whether the recalled event was positive, negative, or neutral to the individual. Table 1 presents the number of subjects giving positive, negative, or neutral descriptions, in relation to specificity of recall. There is a significant difference between response categories $\left[\chi^{2}(2)=8.62, p<.02\right]$ : the specific recollections have more instances of negative episodes. Examples of negative episodes involved a stolen wallet and a broken-down automobile.

\section{DISCUSSION}

Most people initially believe that the task of reconstructing an episode from a specific day in their lives is difficult, if not impossible. Within $5 \mathrm{~min}$, however, all of our subjects provided at least a general recollection of where they had been and what they had been doing; most of these subjects also had specific recall of some details of that day. The protocols suggest that subjects with specific recollection have made contact with an analogic representation, such as a visual image, or a reevocation of an emotional experience.

How do subjects achieve memories that a few minutes earlier they thought were impossible? Both general and specific recollections of August 8,1985 , made use of temporal landmarks. For a number of subjects, the second week in August was the beginning or end of their va-

Table 1

Number of Respondents Giving Positive, Neutral, and Negative Recollections, by Specificity of Recall

\begin{tabular}{cccc}
\hline & Positive & Neutral & Negative \\
\hline General & 3 & 12 & 1 \\
Specific & 2 & 9 & 8 \\
\hline
\end{tabular}

Note $-\chi^{2}(2)=8.62, p<.02$. cations. For 2 subjects, August 8 was the date of a final exam. One subject had expected August 7 to be the end of the world.

Is there a difference between the content of protocols with detailed recall and that of protocols consisting only of general recollections? Many studies support the so-called Pollyanna principle, namely that we have superior recall for pleasant events. Waldvogel (1948), for example, asked adults to recollect early childhood memories. He found that $50 \%$ of these memories were pleasant, $30 \%$ were unpleasant, and $20 \%$ were neutral. In our research, specific recollections of August 8, 1985, had significantly more instances of negative episodes, even when occurring within a context, such as a vacation, that would typically be considered a positive experience. Our question, unlike Waldvogel's, was not open-ended, but rather focused upon events of a specific day. As such, our study is similar to those on flashbulb memories and eyewitness testimony. It is interesting that all of the flashbulb memory studies have been associated with violent events, such as assassinations. Similarly, studies on eyewitness testimony are typically about crimes. It may be that violent events more often leave a lasting, vivid impression. A follow-up study might ask for subjects' self-reports on vividness of recall as well as emotional tonality.

Verification is a problem in the interpretation of studies such as this. To what extent are the subjects' accounts accurate? Experiments on story recall and the limitations of eyewitness testimony have shown that events not consistent with one's memory schemata are often forgotten or accounted for through unconscious fabrications. In our study, only 5 of the 35 individuals were able to produce evidence that would verify or falsify their story. Sheingold and Tenney (1982) were able to obtain confirmatory evidence by asking mothers to verify their child's recollections of the events surrounding a younger sibling's birth. Seventy percent of the recollections were confirmed, regardless of the time passed since that birth.

To what extent do the present findings generalize to real-life situations, in which investigators ask witnesses to recount specific events long past? Compared with early laboratory studies of witness recall (e.g., Munsterberg, 1908), current researchers fortunately are showing increased care to qualify their findings, based on questions of external validity (McCloskey \& Egeth, 1983; Melton, 1987). Here, where President Reagan's query was the impetus for this research (Reynolds, 1987), we should emphasize a number of differences for the reader to consider between the situation facing research repondents such as ours and that typically facing real-life witnesses, in this case President Reagan: (1) Aided recall. We can expect a President to have and use some written record to substantiate his unaided recall. (2) Latency. There is a time span of more than $5 \mathrm{~min}$ to achieve recall. (3) Content. The content of the event is actually of greater importance than the date it occurred. (4) Accuracy. The dependent variable is more his accuracy of recall than his certainty-two variables that are not identical (Kassin, 1985). (5) Sanctions. He has some obligation to give a correct answer, with penalties for incorrectness. On most of these points, one might expect a typical real-life witness to demonstrate a recall superior to that of the respondents in this study.

\section{REFERENCES}

Brown, R., \& Kulik, J. (1977). Flashbulb memories. Cognition, 5, 73-79.

Colegrove, F. W. (1899). Individual memories. American Journal of Psychology, 10, 228-255.

Glass, A. L., \& HolyoaK, K. J. (1986). Cognition. New York: Random House.

KASSIN, S. (1985). Eyewitness identification: Retrospective selfawareness and the accuracy-confidence correlation. Journal of Personality \& Social Psychology, 49, 878-893.

Linton, M. (1975). Memory for real-world events. In D. A. Norman \& D. E. Rumelhart (Eds.), Explorations in cognition. San Francisco: Freeman.

McCloskey, M., \& Egeth, H. (1983). A time to speak, or a time to keep silence? American Psychologist, 38, 573-575. 
Melton, G. (1987). Bringing psychology to the legal system. American Psychologist, 42, 488-495.

Munsterberg, H. (1908). On the witness stand. New York: McClure. ReYnolds, R. I. (1987, March 8). August 8, 1985 recalled. The New York Times, p. D16.

Sheingold, K., \& Tenney, Y. J. (1982). Memory for a salient child- hood event. In U. Neisser (Ed.), Memory observed: Remembering in natural contexts. San Francisco: W. H. Freeman.

WALDVOGEL, S. (1948). The frequency and affective character of childhood memories. Psychological Monographs, 62(Whole No. 291).

(Manuscript received for publication June 23, 1987.) 